Article

\title{
Association between Urinary Phthalate Metabolites and Markers of Endothelial Dysfunction in Adolescents and Young Adults
}

\author{
Po-Ching Chu ${ }^{1,2}$, Charlene $\mathrm{Wu}^{3}$ and Ta-Chen $\mathrm{Su}{ }^{1,2,4,5, *,+}$ \\ 1 Department of Environmental and Occupational Medicine, College of Medicine, National Taiwan University, \\ No. 1 Ren'ai Road Section 1, Taipei 10051, Taiwan; pcchu@ntuh.gov.tw \\ 2 Department of Environmental and Occupational Medicine, National Taiwan University Hospital, No. 7 \\ Chung-Shan South Road, Taipei 10002, Taiwan \\ 3 Global Health Program, College of Public Health, National Taiwan University, Taipei 10055, Taiwan; \\ charlenewu@ntu.edu.tw \\ 4 Division of Cardiology, Department of Internal Medicine, National Taiwan University Hospital, \\ Taipei 10051, Taiwan \\ 5 Institute of Environmental and Occupational Health Sciences, College of Public Health, \\ National Taiwan University, Taipei 10055, Taiwan \\ * Correspondence: tachensu@gmail.com; Tel.: +886-2-2312-3456 (ext. 66719 or 67183); Fax: +886-2-2371-2361 \\ + Director and Clinical Professor, Department of Environmental and Occupational Medicine, \\ National Taiwan University Hospital, Taipei 10002, Taiwan.
}

check for updates

Citation: Chu, P.-C.; Wu, C.; Su, T.-C. Association between Urinary Phthalate Metabolites and Markers of Endothelial Dysfunction in Adolescents and Young Adults. Toxics 2021, 9, 33. https://doi.org/ $10.3390 /$ toxics 9020033

Academic Editors: Greet Schoeters and Po-Chin Huang

Received: 16 December 2020

Accepted: 3 February 2021

Published: 6 February 2021

Publisher's Note: MDPI stays neutral with regard to jurisdictional claims in published maps and institutional affiliations.

Copyright: (c) 2021 by the authors. Licensee MDPI, Basel, Switzerland. This article is an open access article distributed under the terms and conditions of the Creative Commons Attribution (CC BY) license (https:// creativecommons.org/licenses/by/ $4.0 /)$.

\begin{abstract}
Endothelial function is crucial in the pathogenesis of circulatory and cardiovascular toxicity; epidemiologic research investigating the association between phthalate exposure and endothelial dysfunction remains limited. We examined the associations between exposures to specific phthalates (di-2-ethylhexyl phthalate, DEHP; di-n-butyl phthalate, DnBP) and circulating endothelial and platelet microparticles (EMPs and PMPs) in adolescents and young adults. Of the 697 participants recruited, anthropometric measurements and health-related behaviors relevant to cardiovascular risks were collected and assessed. Urine and serum were collected and analyzed with liquid chromatography-tandem mass spectrometry (LC-MS/MS) and flow cytometry. Multiple linear regression indicated that increases in urinary concentrations of $\Sigma$ DEHP and MnBP (mono-n-butyl phthalate), across quartiles, were positively associated with serum EMPs level ( $p$ for trend $<0.001$ and $<0.001 ; \beta=0.798$ and 0.007; standard error $=0.189$ and 0.001 , respectively). Moreover, female and overweight subjects had higher MnBP, and males were more vulnerable to DnBP exposure compared to females. In conclusion, our results demonstrate a dose-response relationship between exposures to phthalates ( $\Sigma$ DEHP and MnBP) and microparticle formation (EMPs and PMPs) in adolescents and young adults. The findings indicate that exposures to phthalates of both low and high-molecular weight are positively associated with microparticle production, and might contribute to endothelial dysfunction; such damage might manifest in the form of atherosclerotic-related vascular diseases. Future in vivo and in vitro studies are warranted to elucidate whether a causal relationship exists between phthalate exposure and EMPs and PMPs.
\end{abstract}

Keywords: phthalates; di-n-butyl phthalate; microparticles; endothelial dysfunction; cardiotoxicity

\section{Introduction}

Phthalate exposure and toxicity is of major concern to public health; among these groups of environmental chemicals, di-2-ethylhexyl phthalate (DEHP) is a key component in consumer and personal care products worldwide. The production volume of dibutyl phthalate (DBP), another commonly used plasticizer, ranged between one and ten million pounds in the USA by 2020; in Asia, the demand for DBP remained high, with an estimated production of 7000 tons in Korea [1,2]. In the European Union (EU), production of DBP 
remained consistent at approximately 10,000 tons [3]. Therefore, in light of the abundant use of DEHP and DBP [1], the health hazards posed to the general population through inhalation, ingestion, and dermal contact with both natural and man-made products continue to exist. Based on the EU risk assessment report, DBP exposure poses general systemic toxicity to humans via repeated dermal exposure from aerosol forming activities [4].

Abundant animal study assessed the adverse health effects of phthalates, including endocrine disruption, reproductive toxicity, neurological, renal, and cardiotoxicity [5-9]. Chen et al. reported developmental toxicity from DBP and estrogenic endocrine disrupting activity from DEHP and DBP in zebrafish embryos. Furthermore, these phthalates could cause additional toxicity symptoms such as cardio edema [5]. Another animal toxicity study revealed that rats chronically exposed to high oral doses of DEHP exhibited many noncarcinogenic effects such as changes in clinical hematology and manifestations of increased liver lesions [7]. DEHP exposure during lactational period was also noted to impair insulin signal transduction and oxidation in the cardiac muscle of female progeny rats [8]. In utero exposure to DEHP caused long-term cardiovascular effects in male offspring rats [9]. A review indicated that there was a weak weight-of-evidence regarding the cardiovascular risk of phthalate exposure, and the major DEHP metabolite had cardiotoxic effects in humans [10]. Urinary DEHP level was positively associated with blood pressure in childhood, and the level of DEHP was associated with diabetes and serum insulin levels [11]. In additional to animal experiments, systemic review of both epidemiological and animal toxicity studies concluded that DEHP and DBP exposure may lead to adverse reproductive health outcomes in both males and females $[6,10,12]$. DEHP and DnBP had anti-androgenic effects in males [10,12], which could affect testicle function, and it may lead to male fertility disorders and testicular dysgenesis syndrome [12]. Additionally, the biochemical mechanism through which cardiotoxicity occurs have been reported. DEHP exposure in mice can induce oxidative stress, inhibit acetylcholinesterase activity, and lead to structural alternation of surrounding blood vessels, as reported in previous literature [13]; these disruptions provide evidence that exposure to DEHP may promote the progression of atherosclerosis. Furthermore, Ferguson and associates indicated that mono-n-butyl phthalate (MnBP), the metabolite of di-n-butyl phthalate (DnBP), and the metabolites of DEHP were significantly and positively associated with markers of oxidative stress (bilirubin) and inflammation (fibrinogen, alkaline phosphatase) based on data from participants in the National Health and Nutrition Examination Survey [14].

Endothelial and platelet microparticles (EMPs, CD31+/CD42a-;PMPs, CD31+/CD42a+) have been used as surrogate markers of endothelial dysfunction and cardiovascular diseases [15-20]. Previous literature identified that clinically, EMPs, which can be shed from impaired and/or apoptotic endothelial cells, are indicative of cardiovascular damage $[15,21]$. We noted few articles that explored the association between phthalate exposure and microparticle formation as an indicator of cardiotoxicity; Kataria and colleagues reported a negative association between the metabolites of high-molecular weight phthalate and EMPs [22]. Our previous study in adolescents and young adults found a positive association between mono-2-ethylhexyl phthalate (MEHP), a metabolite of DEHP, and endothelial and platelet microparticles [19]. However, the association between exposure to commonly used phthalates, such as $\Sigma$ DEHP and DnBP, and microparticles is yet to be investigated, especially in adolescents and young adults. Thus, we hypothesize exposures to $\Sigma$ DEHP and DnBP are likely to induce endothelial dysfunction, and initial damage may manifest in increased counts of circulating microparticles in serum; we propose a cross-sectional investigation in a cohort to elucidate whether exposures to DEHP and DnBP are associated with microparticle formation in adolescents and young adults.

\section{Methods}

\subsection{Study Participants}

The YOung TAiwanese Cohort (YOTA) was a nationwide screening program established from 1992 to 2000 for renal diseases among age 6-18 years in Taiwanese schools [23,24]. 
Participants engaging in the screening program were contacted for follow-up examination in 2006-2008. Among the participants who joined the screening program and categorized with elevated blood pressure, 303 residents of Taipei completed the follow-up examination. We randomly reached out to 6390 participants with normal blood pressure and recruited 486 participants from Taipei; the detailed methods are described in our previous study [24]. We further excluded 21 participants due to missing urine samples, and 71 subjects were eliminated because their urinary creatinine concentrations were below $0.3 \mathrm{~g} / \mathrm{L}$ or above $3.0 \mathrm{~g} / \mathrm{L}$, which was based on guidelines published by the World Health Organization and National Institute of Health $[25,26]$. Therefore, 697 participants remained as our total study population. A diagram detailing the selection criteria of study subjects is presented in Figure 1. This study protocol was approved by the Research Ethics Committee of National Taiwan University Hospital. Informed written consent was obtained from each participant and their parents before they participated in the study.

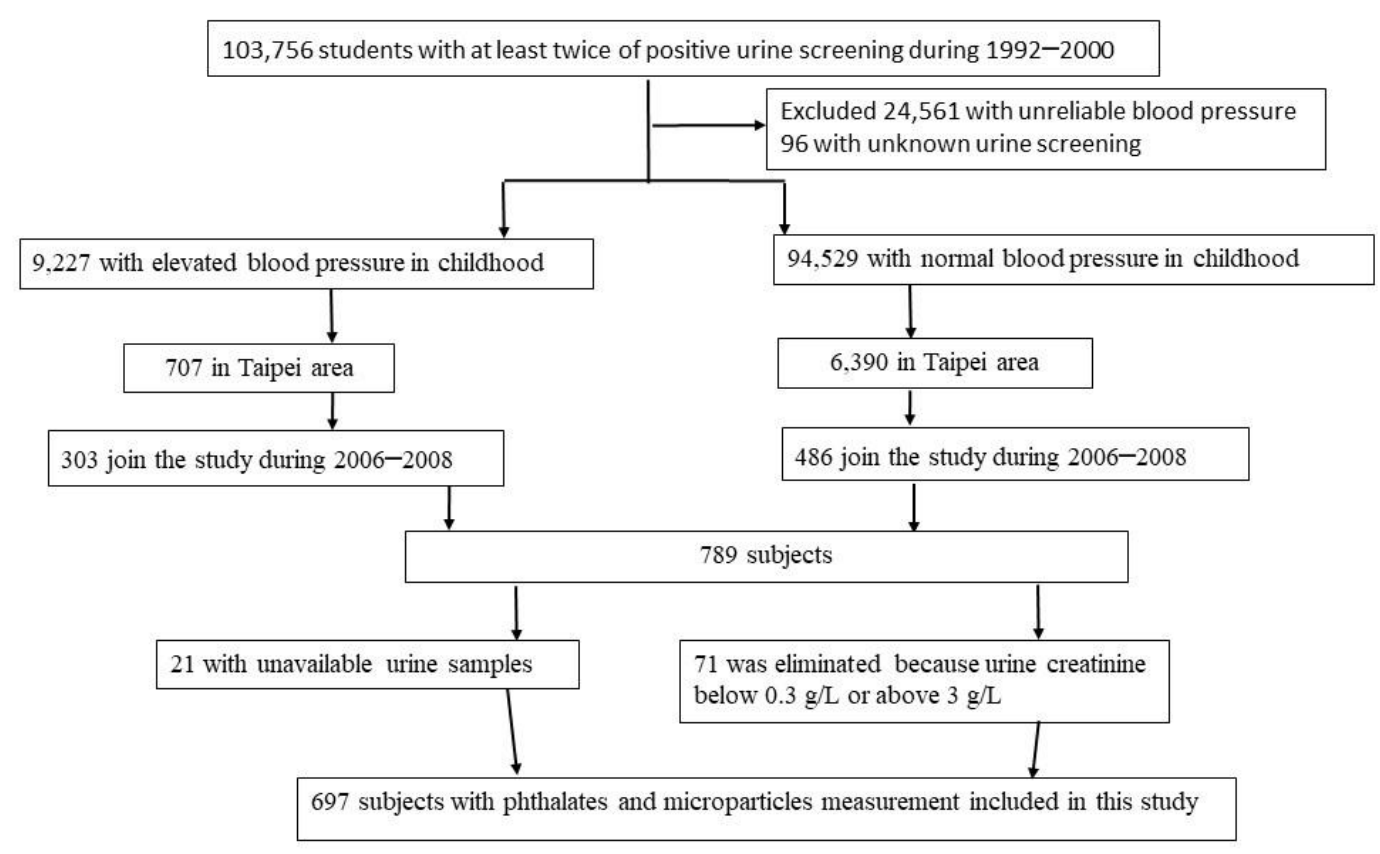

Figure 1. Flow chart of the study population recruitment.

\subsection{Assessment of Personal and Anthropometric Data}

Personal data were obtained from a structured and self-administered questionnaire, including basic demographic data (i.e., age, gender), lifestyle habits (i.e., cigarette smoking, alcohol consumption, physical activity), medication history, and household income. Smoking status was classified into two groups: (1) active smoker and (2) non-active smoker. Alcohol consumption was classified into two groups: (1) current alcohol consumption and (2) non-current alcohol consumption. Physical activity was classified into two groups: (1) regular activity and (2) non-regular activity. Body mass index (BMI) was evaluated as body weight divided by the square of body height $\left(\mathrm{kg} / \mathrm{m}^{2}\right)$; it was classified into two groups: (1) $<24$ and ( 2$) \geq 24$. Household income was classified into two groups: $(1)<50,000$ New Taiwan dollar (NTD)/month, and (2) $\geq 50,000 \mathrm{NTD} /$ month. Two sets of seated blood pressure were recorded after $5 \mathrm{~min}$ of rest with a mercury sphygmomanometer and appropriate cuff size. Hypertension was determined by receiving anti-hypertension medicines currently, or a mean blood pressure of more than or equal to $140 / 90 \mathrm{~mm} \mathrm{Hg}$. 


\subsection{Biochemical Measurements}

Blood samples were obtained in the morning after participants had endured more than eight hours of fasting; subsequent serum samples were stored at $-80{ }^{\circ} \mathrm{C}$ prior to analysis. The serum concentrations of glucose and total cholesterol were measured using an autoanalyzer (Technician RA 2000 Autoanalyzer, Bayer Diagnostic, Mishawaka, India). Diabetes mellitus was determined by the current use of oral hypoglycemic agents or insulin, or a fasting serum glucose of more than or equal to $126 \mathrm{mg} / \mathrm{dL}$. Total cholesterol was classified into two groups: (1) $<200$ and (2) $\geq 200 \mathrm{mg} / \mathrm{dL}$. The coefficient of variation for serum total cholesterol and glucose was under $3 \%$.

\subsection{Analysis of Urine Phthalate Metabolites}

The first-void urine samples in the morning were collected from all participants to analyze urinary metabolites of phthalates, including MEHP, mono(ethyl-5-hydroxyhexyl) phthalate (MEHHP), mono(2-ethly-5-oxoheyl) phthalate (MEOHP), and MnBP. The urine samples were quantitatively analyzed by liquid chromatography-tandem mass spectrometric (LC-MS/MS); the detailed methods were the same as our previous study [27]. Internal quality control was performed applying pooled quality control urines and external quality assurance was assessed using the German External Quality Assessment Scheme for Biological Monitoring (G-EQUAS). The method detection limits of MnBP, MEHP, MEHHP, and MEOHP were 1.0, 0.7, 0.1, and $0.1 \mu \mathrm{g} / \mathrm{L}$, respectively. Laboratory results below the limits of detection were recorded as the detection limit divided by the square root of two [28]. The detection rates for MEHP, MEHHP, MEOHP, and MnBP were 75.18\%, 99.71\%, 100\%, and $99.71 \%$, respectively. The urinary metabolite concentrations were adjusted with urinary creatinine.

\subsection{Measurements of EMPs and PMPS}

EMPs and PMPs were estimated with a flow cytometer using the method based on previous research [26]. The microparticles were measured simultaneously in citrated serum with a pair of fluorescent monoclonal antibodies: phycoerythrin-labeled anti-CD31 (BD Bioscience, San Jose, CA, USA ) and fluorescein isothiocyanate-labeled anti CD42a (BD Bioscience, San Jose, CA, USA). The values of the microparticles are reported as counts $/ \mu \mathrm{L}$.

\subsection{Statistical Analysis}

To determine total exposure to DEHP, we estimated urinary concentrations of the metabolites by summing the molar concentrations of MEHP, MEHHP, and MEOHP as described in previous research (hereafter referred to as $\Sigma$ DEHP in $\mu \mathrm{mol} / \mathrm{g}$ creatinine) [29,30]; all other phthalate metabolites analyzed in this study are expressed in $\mu \mathrm{g} / \mathrm{g}$ creatinine [31-39]. The distribution of different phthalate metabolites according to basic characteristics were analyzed, with urine metabolites concentrations expressed as geometric means and $95 \%$ confidence intervals (95\% CI). The characteristics included the following: age, gender, hypertension, diabetes mellitus, total cholesterol, body mass index, smoking status, alcohol consumption, physical activity, and household income. Similarly, the distribution of EMPs and PMPs among our study participants were analyzed. A Kruskal-Wallis test was performed to examine the abovementioned associations since the distributions were highly skewed; post hoc analysis was subsequently performed. In order to explore the dose-response relationships between the phthalate metabolites and microparticles, the extended model approach with multiple linear regression analyses was applied and potential confounders were adjusted: age, gender, hypertension, diabetes mellitus, total cholesterol, body mass index, smoking status, alcohol consumption, physical activity, and household income. The potential confounders consisted of both continuous variables (age, total cholesterol, BMI), and categorical variables (gender, hypertension, diabetes mellitus, smoking status, alcohol consumption, physical activity, and household income). Based on previous research, the abovementioned factors were associated with endothelial dysfunction or microparticles [32-38]; thus, all factors were selected in the 
regression model. A natural log transformation was performed for the concentrations of $\Sigma$ DEHP, MnBP, EMPs, and PMPs. Further subgroup analyses were performed to examine whether the correlation between phthalate exposure and microparticle formation is affected by the abovementioned confounders. To explore the association between phthalate metabolites and microparticles, a Kruskal-Wallis test was performed to compare different levels of phthalate metabolites across four quartiles of microparticles, and also compare the highest to lowest quartiles. The trend test was modeled according to median value of each quartile of the phthalates to compare the difference of microparticles and was also adjusted for confounders; another set of same analyses were performed on non-diabetic participants. To examine the impact of co-exposure of the DEHP and DnBP on markers of endothelial dysfunction, these metabolites of $\Sigma \mathrm{DEHP}$ and MnBP were put in the same regression model. All statistical analyses were conducted using the SAS version 9.2 software by SAS Institute Inc. (Cary, NC, USA).

\section{Results}

Table 1 details the basic demographic characteristics of the study population and geometric means, including and $95 \%$ confidence interval (CI), of the concentrations of $\Sigma$ DEHP and MnBP. The majority of our study cohort was female $(n=436,62.6 \%)$, with an average age of 21.3 years (standard deviation, $\mathrm{SD}=3.3$ ). The mean concentration of creatinine-adjusted urinary $\Sigma$ DEHP among all participants was $0.23(95 \% \mathrm{CI}=0.21$ $0.25) \mu \mathrm{mol} / \mathrm{g}$ creatinine. The mean concentrations and $95 \%$ CI for MnBP was 38.99 (36.4741.68) $\mu \mathrm{g} / \mathrm{g}$ creatinine. Furthermore, the mean concentration of MnBP was statistically significantly higher among females $(41.43 \mu \mathrm{g} / \mathrm{g}$ creatinine) compared to males ( $35.23 \mu \mathrm{g} / \mathrm{g}$ creatinine; $p=0.003$ ). Diabetic participants had higher mean concentration of $\Sigma D E H P$ compared to their counterparts $(p=0.038)$. Similar statistically significant differences were evident among those who are overweight (BMI $\geq 24)$, as this group of individuals had higher urinary concentrations of $\Sigma \mathrm{DEHP}$ and $\mathrm{MnBP}(p=0.033$ and 0.002 , respectively).

Supplementary Table S1 details the distribution and percentiles of the phthalates, and Supplementary Table S2 outlines the geometric means and 95\% CI of the concentrations of EMPs and PMPs of the study participants, according to basic characteristics. Those under 20 years of age had higher mean counts of EMPs and PMPs than those between the ages of 20 to 30 (with both $p$-values $<0.01$ ). Males had a higher mean counts of EMPs than females (182.45 vs. 127.31 counts $/ \mu \mathrm{L}, p<0.01)$. Moreover, counts of EMPs were statistically significantly higher in those reported with hypertension, diabetes, hypercholesterolemia, and overweight ( $p \leq 0.001,0.03,0.04$, and $<0.001$, respectively).

In Table 2, the multivariate linear regression analysis showed that among males, per unit increase in the natural log-transformed concentration of MnBP was positively associated with higher natural log-transformed EMPs when compared to females. The subgroup analysis for different age groups showed that $\Sigma D E H P$ levels were positively associated with counts of EMPs for those under 20 years of age and those between the ages of 20 to 30 ( $p$-value 0.013 and $<0.001$; coefficient $=0.257$ and 0.211 , respectively). Similarly, MnBP levels were positively associated with counts of EMPs for those under 20 years of age and those between the ages of 20 to 30 ( $p$-value 0.004 and $<0.010$; coefficient $=0.299$ and 0.161 , respectively).

We documented the geometric mean concentrations of creatinine-adjusted urinary $\Sigma \mathrm{DEHP}$ and MnBP, analyzed across increasing quartiles of serum counts of EMPs, in Table 3. Our results demonstrated that differences in levels of $\Sigma$ DEHP and MnBP were statistically significant $(p<0.001)$, with urinary $\Sigma$ DEHP and MnBP concentrations significantly increased with serum EMP counts (quartile 4 compared to quartile 1). The same analysis was also performed across quartiles of serum counts of PMPs, and results showed the concentrations of $\Sigma$ DEHP significantly increased with serum PMP levels. 
Table 1. Basic characteristics of the sample subjects including geometric mean and $95 \%$ confidence interval of the creatinine-adjusted urinary $\Sigma$ DEHP and MnBP ${ }^{\text {a }}$.

\begin{tabular}{|c|c|c|c|}
\hline \multirow{2}{*}{ Characteristics } & $\mathbf{N}$ & $\Sigma$ DEHP & MnBP \\
\hline & 697 & $0.23(0.21-0.25)$ & $38.99(36.47-41.68)$ \\
\hline \multicolumn{4}{|l|}{ Age } \\
\hline $12-19$ & 204 & $0.25(0.22-0.28)$ & $40.01(35.53-45.05)$ \\
\hline $20-30$ & 493 & $0.22(0.20-0.24)$ & $38.58(35.58-41.82)$ \\
\hline \multicolumn{4}{|l|}{ Gender } \\
\hline Male & 261 & $0.20^{\mathrm{c}}(0.17-0.22)$ & $35.23^{c}(31.53-39.36)$ \\
\hline Female & 436 & $0.25^{\mathrm{c}}(0.23-0.28)$ & $41.43^{c}(38.12-45.03)$ \\
\hline \multicolumn{4}{|l|}{ Hypertension } \\
\hline Yes & 62 & $0.27(0.20-0.36)$ & $43.84(34.88-55.12)$ \\
\hline No & 635 & $0.23(0.21-0.24)$ & $38.55(35.94-41.34)$ \\
\hline \multicolumn{4}{|l|}{ Diabetes mellitus } \\
\hline Yes & 17 & $0.35^{b}(0.23-0.52)$ & $45.78(30.26-69.24)$ \\
\hline No & 680 & $0.23^{b}(0.21-0.25)$ & $38.83(36.29-41.56)$ \\
\hline \multicolumn{4}{|l|}{$\begin{array}{c}\text { Total cholesterol } \\
(\mathrm{mg} / \mathrm{dL})\end{array}$} \\
\hline$<200$ & 154 & $0.21(0.18-0.25)$ & $41.96(36.80-47.85)$ \\
\hline$\geq 200$ & 543 & $0.23(0.22-0.25)$ & $38.19(35.34-41.25)$ \\
\hline \multicolumn{4}{|l|}{$\begin{array}{l}\text { Body mass index } \\
\qquad\left(\mathrm{kg} / \mathrm{m}^{2}\right)\end{array}$} \\
\hline$<24$ & 544 & $0.22^{b}(0.20-0.24)$ & $36.64^{c}(33.94-39.55)$ \\
\hline$\geq 24$ & 153 & $0.26^{\mathrm{b}}(0.23-0.31)$ & $48.65^{\mathrm{c}}(42.67-55.47)$ \\
\hline \multicolumn{4}{|l|}{ Smoking status } \\
\hline Non-active smoker & 579 & $0.24(0.22-0.26)$ & $39.84(37.06-42.82)$ \\
\hline Active smoker & 118 & $0.21(0.17-0.25)$ & 35.09 (29.51-41.72) \\
\hline \multicolumn{4}{|l|}{ Alcohol consumption } \\
\hline Yes & 44 & $0.21(0.16-0.28)$ & $39.79(31.08-50.94)$ \\
\hline No & 653 & $0.23(0.21-0.25)$ & $38.94(36.33-41.74)$ \\
\hline \multicolumn{4}{|l|}{ Physical activity } \\
\hline Yes & 508 & $0.22(0.20-0.24)$ & $38.46(35.57-41.59)$ \\
\hline No & 189 & $0.25(0.22-0.29)$ & $40.44(35.54-46.03)$ \\
\hline \multicolumn{4}{|l|}{ Household income } \\
\hline$<50,000$ NTD/month & 260 & $0.24(0.21-0.27)$ & $36.84(32.54-41.71)$ \\
\hline$\geq 50,000 \mathrm{NTD} /$ month & 437 & $0.22(0.21-0.25)$ & $40.33(37.34-43.55)$ \\
\hline
\end{tabular}

Table 2. Linear regression coefficients (standard error) of natural log-transformed endothelial microparticles (EMPs) and platelet microparticles (PMPs) with per unit increase in natural log-transformed $\Sigma$ DEHP and MnBP in multiple linear regression model ${ }^{a}$ for overall and subgroup population.

\begin{tabular}{|c|c|c|c|c|c|c|c|c|}
\hline & \multicolumn{4}{|c|}{ 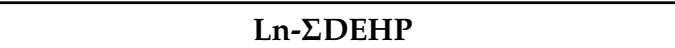 } & \multicolumn{4}{|c|}{ Ln-MnBP } \\
\hline & Ln-EMPs & $p$-Value & Ln-PMPs & $p$-Value & Ln-EMPs & $p$-Value & Ln-PMPs & $p$-Value \\
\hline Overall & $\begin{array}{c}0.236 \\
(0.046)\end{array}$ & $<0.001$ & $\begin{array}{c}0.186 \\
(0.065)\end{array}$ & 0.005 & $\begin{array}{c}0.208 \\
(0.052)\end{array}$ & $<0.001$ & $\begin{array}{c}0.036 \\
(0.074)\end{array}$ & 0.626 \\
\hline Age & & & & & & & & \\
\hline $12-19$ & $\begin{array}{c}0.257 \\
(0.102)\end{array}$ & 0.013 & $\begin{array}{c}0.174 \\
(0.129)\end{array}$ & 0.177 & $\begin{array}{c}0.299 \\
(0.103)\end{array}$ & 0.004 & $\begin{array}{c}0.078 \\
(0.131)\end{array}$ & 0.544 \\
\hline $20-30$ & $\begin{array}{c}0.211 \\
(0.053)\end{array}$ & $<0.001$ & $\begin{array}{c}0.171 \\
(0.077)\end{array}$ & 0.026 & $\begin{array}{c}0.161 \\
(0.062)\end{array}$ & 0.010 & $\begin{array}{l}-0.004 \\
(0.089)\end{array}$ & 0.964 \\
\hline Gender & & & & & & & & \\
\hline Male & $\begin{array}{c}0.231 \\
(0.073)\end{array}$ & 0.002 & $\begin{array}{c}0.138 \\
(0.110)\end{array}$ & 0.210 & $\begin{array}{c}0.246 \\
(0.082)\end{array}$ & 0.003 & $\begin{array}{l}-0.045 \\
(0.124)\end{array}$ & 0.714 \\
\hline
\end{tabular}


Table 2. Cont.

\begin{tabular}{|c|c|c|c|c|c|c|c|c|}
\hline & \multicolumn{4}{|c|}{ 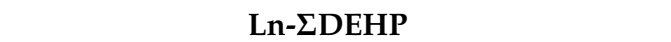 } & \multicolumn{4}{|c|}{ Ln-MnBP } \\
\hline & Ln-EMPs & $p$-Value & Ln-PMPs & $p$-Value & Ln-EMPs & $p$-Value & Ln-PMPs & $p$-Value \\
\hline Female & $\begin{array}{c}0.233 \\
(0.060)\end{array}$ & $<0.001$ & $\begin{array}{c}0.220 \\
(0.081)\end{array}$ & 0.007 & $\begin{array}{c}0.183 \\
(0.069)\end{array}$ & 0.008 & $\begin{array}{c}0.083 \\
(0.923)\end{array}$ & 0.367 \\
\hline \multicolumn{9}{|l|}{ Hypertension } \\
\hline No & $\begin{array}{c}0.288 \\
(0.049)\end{array}$ & $<0.001$ & $\begin{array}{c}0.171 \\
(0.069)\end{array}$ & 0.014 & $\begin{array}{c}0.210 \\
(0.054)\end{array}$ & $<0.001$ & $\begin{array}{c}0.051 \\
(0.077)\end{array}$ & 0.508 \\
\hline Yes & $\begin{array}{c}0.273 \\
(0.166)\end{array}$ & 0.107 & $\begin{array}{c}0.321 \\
(0.214)\end{array}$ & 0.140 & $\begin{array}{c}0.133 \\
(0.226)\end{array}$ & 0.560 & $\begin{array}{l}-0.063 \\
(0.291)\end{array}$ & 0.829 \\
\hline \multicolumn{9}{|l|}{ Diabetes mellitus } \\
\hline No & $\begin{array}{l}0.228 \\
(0.046)\end{array}$ & $<0.001$ & $\begin{array}{c}0.177 \\
(0.066)\end{array}$ & 0.007 & $\begin{array}{c}0.208 \\
(0.052)\end{array}$ & $<0.001$ & $\begin{array}{c}0.032 \\
(0.074)\end{array}$ & 0.663 \\
\hline Yes & $\begin{array}{c}0.109 \\
(1.052)\end{array}$ & 0.921 & $\begin{array}{l}1.323 \\
(1.397)\end{array}$ & 0.380 & $\begin{array}{l}-0.324 \\
(0.584)\end{array}$ & 0.599 & $\begin{array}{c}0.177 \\
(0.848)\end{array}$ & 0.842 \\
\hline \multicolumn{9}{|l|}{ Total cholesterol (mg/dL) } \\
\hline$<200$ & $\begin{array}{c}0.210 \\
(0.051)\end{array}$ & $<0.001$ & $\begin{array}{c}0.141 \\
(0.071)\end{array}$ & 0.049 & $\begin{array}{c}0.188 \\
(0.056)\end{array}$ & $<0.001$ & $\begin{array}{c}0.009 \\
(0.078)\end{array}$ & 0.906 \\
\hline$\geq 200$ & $\begin{array}{l}0.349 \\
(0.114)\end{array}$ & 0.003 & $\begin{array}{l}0.384 \\
(0.167)\end{array}$ & 0.023 & $\begin{array}{c}0.323 \\
(0.140)\end{array}$ & 0.022 & $\begin{array}{c}0.192 \\
(0.205)\end{array}$ & 0.351 \\
\hline \multicolumn{9}{|l|}{ BMI status $\left(\mathrm{kg} / \mathrm{m}^{2}\right)$} \\
\hline$<24$ & $\begin{array}{c}0.159 \\
(0.053)\end{array}$ & 0.003 & $\begin{array}{c}0.135 \\
(0.072)\end{array}$ & 0.062 & $\begin{array}{c}0.171 \\
(0.058)\end{array}$ & 0.004 & $\begin{array}{c}0.059 \\
(0.080)\end{array}$ & 0.464 \\
\hline$\geq 24$ & $\begin{array}{c}0.515 \\
(0.103)\end{array}$ & $<0.001$ & $\begin{array}{c}0.432 \\
(0.160)\end{array}$ & 0.008 & $\begin{array}{c}0.406 \\
(0.129)\end{array}$ & 0.002 & $\begin{array}{c}0.008 \\
(0.195)\end{array}$ & 0.967 \\
\hline \multicolumn{9}{|l|}{ Smoking status } \\
\hline Non-active smoker & $\begin{array}{c}0.236 \\
(0.052)\end{array}$ & $<0.001$ & $\begin{array}{c}0.158 \\
(0.073)\end{array}$ & 0.032 & $\begin{array}{c}0.180 \\
(0.059)\end{array}$ & 0.002 & $\begin{array}{l}0.0004 \\
(0.082)\end{array}$ & 0.995 \\
\hline Active smoker & $\begin{array}{c}0.224 \\
(0.107)\end{array}$ & 0.039 & $\begin{array}{c}0.278 \\
(0.159)\end{array}$ & 0.082 & $\begin{array}{c}0.336 \\
(0.116)\end{array}$ & 0.005 & $\begin{array}{c}0.205 \\
(0.177)\end{array}$ & 0.248 \\
\hline \multicolumn{9}{|l|}{ Alcoholic consumption } \\
\hline No & $\begin{array}{c}0.228 \\
(0.048)\end{array}$ & $<0.001$ & $\begin{array}{c}0.196 \\
(0.066)\end{array}$ & 0.003 & $\begin{array}{c}0.200 \\
(0.053)\end{array}$ & $<0.001$ & $\begin{array}{c}0.049 \\
(0.074)\end{array}$ & 0.509 \\
\hline Yes & $\begin{array}{c}0.360 \\
(0.228)\end{array}$ & 0.123 & $\begin{array}{c}-0.039 \\
(0.404)\end{array}$ & 0.923 & $\begin{array}{c}0.422 \\
(0.256)\end{array}$ & 0.109 & $\begin{array}{l}-0.225 \\
(0.454)\end{array}$ & 0.623 \\
\hline \multicolumn{9}{|l|}{ Physical activity } \\
\hline No & $\begin{array}{c}0.268 \\
(0.082)\end{array}$ & 0.001 & $\begin{array}{c}0.308 \\
(0.115)\end{array}$ & 0.008 & $\begin{array}{c}0.141 \\
(0.097)\end{array}$ & 0.148 & $\begin{array}{l}-0.010 \\
(0.136)\end{array}$ & 0.940 \\
\hline Yes & $\begin{array}{c}0.222 \\
(0.056)\end{array}$ & $<0.001$ & $\begin{array}{c}0.131 \\
(0.079)\end{array}$ & 0.098 & $\begin{array}{c}0.218 \\
(0.063)\end{array}$ & $<0.001$ & $\begin{array}{c}0.030 \\
(0.088)\end{array}$ & 0.730 \\
\hline \multicolumn{9}{|l|}{ Household income } \\
\hline$<50,000$ NTD/month & $\begin{array}{c}0.242 \\
(0.071)\end{array}$ & $<0.001$ & $\begin{array}{c}0.164 \\
(0.101)\end{array}$ & $<0.105$ & $\begin{array}{c}0.167 \\
(0.079)\end{array}$ & $<0.036$ & $\begin{array}{l}-0.082 \\
(0.110)\end{array}$ & 0.459 \\
\hline$\geq 50,000 \mathrm{NTD} /$ month & $\begin{array}{c}0.232 \\
(0.062)\end{array}$ & $<0.001$ & $\begin{array}{c}0.182 \\
(0.087)\end{array}$ & 0.037 & $\begin{array}{c}0.239 \\
(0.071)\end{array}$ & $<0.001$ & $\begin{array}{c}0.102 \\
(0.100)\end{array}$ & 0.308 \\
\hline
\end{tabular}

DEHP: di-2-ethylhexyl phthalate; MnBP: mono-n-butyl phthalate; a Models were adjusted for age, gender, BMI, total cholesterol, hypertension, diabetes, smoking, alcohol consumption, physical activity, and household income.

Table 3. Geometric means and standard errors of creatinine-adjusted urinary concentration of $\Sigma$ DEHP and MnBP by quartile distribution of EMPs and PMPs a .

\begin{tabular}{ccccccc}
\hline & \multicolumn{9}{c}{ EMPs } \\
\cline { 2 - 7 } Phthalate & $\begin{array}{c}\text { Quartile 1 } \\
\text { Metabolites }\end{array}$ & $\begin{array}{c}\text { Quartile 2 } \\
(\mathrm{n}=173)\end{array}$ & $\begin{array}{c}\text { Quartile 3 } \\
(\mathrm{n}=172)\end{array}$ & $\begin{array}{c}\text { Quartile 4 } \\
(\mathrm{n}=176)\end{array}$ & $p-1$ value $^{\mathrm{b}}$ & $p$-2 value \\
& $<52.86$ & $52.86-145.71$ & $145.71-364.29$ & $>364.29$ & & \\
\hline$\Sigma$ cEHP & $0.206(0.016)$ & $0.194(0.014)$ & $0.226(0.017)$ & $0.310(0.022)$ & $<0.001$ & $<0.001$ \\
MnBP & $34.811(2.425)$ & $32.980(2.291)$ & $42.093(2.723)$ & $47.813(3.096)$ & $<0.001$ & $<0.001$ \\
\hline
\end{tabular}


Table 3. Cont.

\begin{tabular}{|c|c|c|c|c|c|c|}
\hline & \multicolumn{4}{|c|}{ PMPs } & \multirow[b]{2}{*}{$p-1$ value $^{\mathrm{b}}$} & \multirow[b]{2}{*}{$p-2$ value ${ }^{c}$} \\
\hline & $\begin{array}{l}\text { Quartile } 1 \\
(\mathrm{n}=173) \\
<1062.86\end{array}$ & $\begin{array}{c}\text { Quartile 2 } \\
(\mathrm{n}=176) \\
1062.86-3628.57\end{array}$ & $\begin{array}{c}\text { Quartile 3 } \\
(\mathrm{n}=172) \\
3628.57-12040.0\end{array}$ & $\begin{array}{l}\text { Quartile } 4 \\
(\mathrm{n}=176) \\
>12040.0\end{array}$ & & \\
\hline$\Sigma \mathrm{DEHP}$ & 0.195 (0.015) & $0.218(0.015)$ & $0.251(0.020)$ & $0.262(0.020)$ & 0.0150 & 0.0026 \\
\hline MnBP & $36.250(2.255)$ & $40.35(2.676)$ & $41.861(3.295)$ & $37.704(2.388)$ & 0.4776 & 0.4826 \\
\hline
\end{tabular}

DEHP: di-2-ethylhexyl phthalate; MnBP: mono-n-butyl phthalate; EMP: endothelial microparticles; PMP: platelet microparticles. ${ }^{a}$ Unit: $\Sigma \mathrm{DEHP}$ as $\mu \mathrm{mol} / \mathrm{g}$ creatinine, and others as $\mu \mathrm{g} / \mathrm{g}$ creatinine. EMPs and PMPs as counts $/ \mu \mathrm{L} .{ }^{\mathrm{b}} p-1$ value was Kruskal-Wallis test for medians. ${ }^{c} p$-2 value was for microparticles quartile 4 compared with quartile 1 .

In Figure 2, the multivariable linear regression analysis showed that participants possessing higher quartiles of urinary $\Sigma$ DEHP and MnBP presented with higher serum natural log-transformed EMPs than those in lower quartiles ( $p$ for trend $<0.001$ and $<0.001$; coefficient $=0.798$ and 0.007 ; standard error $=0.189$ and 0.001 , respectively). Compared to the lowest quartile levels of MnBP, those in the highest quartile also had correspondingly higher counts of serum natural log-transformed EMPs, which appeared to have increased by more than 1.16 -fold ( $p$-value $<0.001$ ). Furthermore, as concentrations of $\Sigma$ DEHP increased across quartiles, the levels of natural log-transformed PMPs increased significantly ( $p$ for trend $=0.015$ ); the abovementioned associations remain among non-diabetic participants (Table S3). In Table 4, the multivariable linear regression analysis for co-exposures to DEHP and DnBP on both types of microparticles (EMPs and PMPs) showed that the increases in $\Sigma D E H P$ and MnBP exposures from the 25th to the 75th percentile (i.e., an interquartile range change) were associated with the increases in EMPs by the multiplicative factors of 1.258 (95\% CI: 1.122, 1.411) and 1.144 (95\% CI: 1.022, 1.281), respectively. The increase in $\Sigma D E H P$ was associated with the increase in PMPs by the multiplicative factor of 1.263 (95\% CI: 1.072, 1.488), but MnBP was not associated with PMPs.

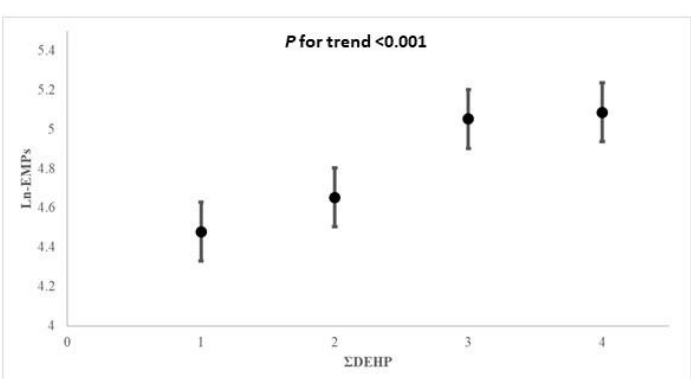

(a)

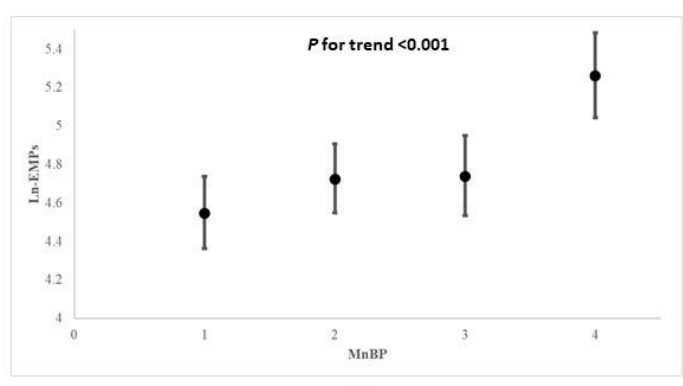

(c)

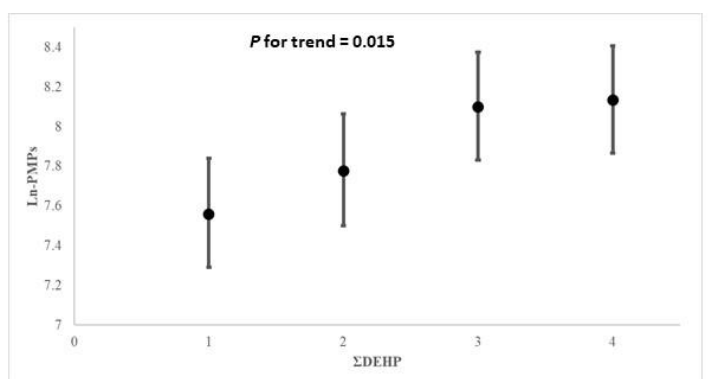

(b)

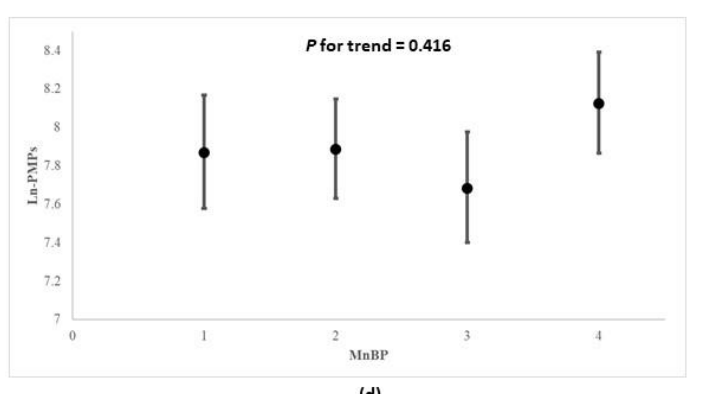

(d)

Figure 2. Geometric mean values and $95 \%$ confidence intervals of natural log-transformed EMPs and PMPs according to quartile concentrations of urinary $\Sigma \mathrm{DEHP}$ and $\mathrm{MnBP}^{\mathrm{a}}$ in multiple linear regression model ${ }^{\mathrm{b}}$. (a) $\Sigma \mathrm{DEHP}$ and Ln-EMPs, (b) $\Sigma$ DEHP and Ln-PMPs, (c) MnBP and Ln-EMPs, (d) MnBP and Ln-PMPs. DEHP: di-2-ethylhexyl phthalate; MnBP: mono-n-butyl phthalate; EMP: endothelial microparticles; PMP: platelet microparticles. ${ }^{\text {a }} \Sigma$ DEHP as $\mu \mathrm{mol} / \mathrm{g}$ creatinine, and others as $\mu \mathrm{g} / \mathrm{g}$ creatinine. EMPs and PMPs as counts $/ \mu \mathrm{L} .{ }^{\mathrm{b}} \mathrm{p}$ for trend analysis-value was modeled according to median value of each quartile of each phthalates metabolites, and was adjusted for age, gender, body mass index, total cholesterol, hypertension, diabetes, smoking, alcohol consumption, physical activity, and household income. 
Table 4. Multiplicative factors (95\% confidence intervals) for a change in serum endothelial and platelet microparticle level ${ }^{\mathrm{a}}$ associated with an interquartile range change in urinary phthalate metabolites level ${ }^{b}$ in multiple linear regression model $^{\mathrm{c}}$.

\begin{tabular}{ccccc}
\hline Phthalate Metabolites & \multicolumn{2}{c}{ Microparticles } & \multicolumn{2}{c}{ PMPs $^{\mathbf{d}}$} \\
\cline { 2 - 5 } & \multicolumn{2}{c}{ EMPs ${ }^{\mathbf{d}}$} & & $p$-value \\
\hline SDEHP & $1.258(1.122,1.411)$ & $p$-value & 0.005 \\
MnBP & $1.144(1.022,1.281)$ & $<0.001$ & $1.263(1.072,1.488)$ & 0.594 \\
\hline
\end{tabular}

DEHP: di-2-ethylhexyl phthalate; MnBP: mono-n-butyl phthalate; EMPs: endothelial microparticle; PMPs: platelet microparticle; SE: standard error. ${ }^{a}$ Natural $\log$ transformations of EMPs and PMPs were used. ${ }^{b}$ Natural log transformations of $\Sigma D E H P$ and MnBP were used. ${ }^{\mathrm{c}}$ Models were adjusted for age, gender, BMI, total cholesterol, hypertension, diabetes, smoking, alcohol consumption, physical activity, and household income. ${ }^{\mathrm{d}}$ Multiplicative factors represent a multiplicative change in microparticle level for an interquartile range change in phthalate level after back-transformation of both microparticle and phthalate levels. For an interquartile range change in phthalate level, a factor $<1.0$ shows a multiplicative decrease in microparticle level, and a factor $>1.0$ shows a multiplicative increase in microparticle level.

\section{Discussion}

Results yielded from our present study indicated significant positive associations existed between phthalate exposure and the formation of microparticles, which might be indicative of endothelial dysfunction. Specifically, our study showed as urinary concentrations of $\Sigma \mathrm{DEHP}$ and MnBP increased across quartiles, serum EMPs increased correspondingly. Moreover, increasing urinary concentrations of $\Sigma \mathrm{DEHP}$ was positively associated with higher serum PMPs levels. Since the formation of EMPs was symptomatic of cell apoptosis and the breakdown of cell-to-cell communication, and that of PMPs indicated stress and thrombus formation [39,40], both of which forewarn and can aggravate circulatory and cardiovascular diseases, our findings suggested exposure to DnBP might be associated with endothelial dysfunction, and such damage might manifest in the form of atherosclerotic-related vascular diseases in later life.

The present study focused on adolescents and young adults because this population may be potentially vulnerable to the toxic effects of phthalates. Since their organs are incompletely developed [41], the anatomical and physiological differences may affect the bioavailability of phthalates [42]. Furthermore, previous researchers indicated that exposure to DEHP and DnBP varied by age in adolescents and young adults [41,43,44]. For example, Fierens and colleagues indicated that exposure rate of DEHP increased with age, but the rate of DnBP decreased with age in Belgian population [43]. The dietary exposure to DEHP and DBP among different age group of children and adolescents in the Spanish population varied [41], and several consumer products were age group specific [42]. The aforementioned reported differences in dietary lifestyles or consumer products used in across age groups may explain these disparities on exposure. Furthermore, legislations about the use of phthalates may differ between countries, and these differences may also affect the exposure [43].

Previous in vivo animal studies reported that mice treated with DEHP through stimulating low-density lipoprotein oxidation presented with aggravated prognosis of hyperlipidemia, systemic inflammation, and atherosclerosis [45]. Our previous epidemiologic research reported that such link existed in young people, as we reported that DEHP and DnBP exposure was directly associated with increased risk of subclinical atherosclerosis, as well as coronary heart disease $[27,46]$. The results of our present study showed the aforementioned manifestations may be partially attributable to the increase in serum levels of EMPs and PMPs. Furthermore, evidence from our investigation imply that the increase in exposure to phthalates of both low and high molecular weight was positively correlated with increased concentrations of serum microparticle. Although such finding differs from previous literature [22], our study design echoes the recommendation of Kataria et al. and expanded the sample size. Furthermore, our study focused exclusively on phthalate exposure; therefore, we eliminated any potential interference brought on by 
bispenols. Although the exact biochemical mechanism remains uncertain, previous literature reported that MnBP may increase urinary biomarkers of oxidative stress, including 8-hydroxydeoxyguanosine and 8-isoprostane [47], which could explain the association between MnBP and endothelial dysfunction. Higher mean of urine MnBP concentrations was also reported to be associated with increased risk of stroke [48]. The possible reasons accounting for the association between MnBP and stroke include disturbance of the glycolytic pathway, which also distresses the production of cardiomyocytes and thus disrupts contractile function of the heart [49]. Although previous findings revealed an increased microparticle count to be associated with morbidities such as obesity, chronic kidney disease, and Henoch-Schonlein vasculitis, the mechanisms of microparticle formations remain elusive [50-52]. Additionally, prior reports indicated phthalates can induce cellular apoptosis [50,51]. Specifically, MEHP can adversely affect human umbilical vein endothelial cells via reactive oxygen species-mediated mitochondria-dependent pathway [53]. Since phthalates are known to induce oxidative stress, and oxidant stress contributes to endothelial dysfunction and arterial stiffness [22], we postulate that this may be the pathway through which exposure to plasticizers may contribute to endothelial dysfunction and the subclinical atherosclerotic in our young population. As previously reported in the research by Kataria and colleagues, the increase of high molecular weight phthalate metabolites was associated with altered levels of EMPs [22]. Trasande and colleagues also found that the increase of metabolites of DEHP was positively associated with albuminuria, which is an indicator of endothelial dysfunction [54]. Furthermore, it is worth noting that concentrations of DnBP metabolite found in our adolescents and young adults may be higher than that of other studies conducted considering that Taiwan banned the use of short-chain phthalate in children's toys and care articles in 2011, which is much later compared to the USA, Canada, and the EU [55].

Since female and overweight participants presented with higher MnBP concentration, we postulate that a gender difference exists. This proposed notion was consistent with a previous report which found that both women $(\geq 18$ years) and girls ( $<18$ years) had higher MnBP compared with males [44]. Although present study indicated that females had higher mean concentration of MnBP, the per unit increase in the concentration of MnBP among males was positively associated with higher level of EMPs when compared to females. Even though previous studies showed gender-related differences do not contribute to the number of circulating EMPs, both studies focused on middle-aged population, and not on adolescents and young adults [56,57]. Considering that gender may modify the associations between MnBP and cardiovascular risk factors [58], future research on how gender-specific differences affect microparticle formation and cardiotoxicity is warranted. Moreover, the present study found overweight subjects had higher MnBP and males were more vulnerable to DnBP exposure compared to females, and the findings were similar with Buser et al. [59] showing that childhood and adulthood with overweight had higher MnBP compared those with normal weight, and low molecular weight phthalate metabolites (e.g., $\mathrm{MnBP}$ ) were associated with higher odds for obesity in male children and adolescents.

Limitations of this study should be noted. First, although results from our crosssectional study revealed that meaningful associations existed between exposure to different types of phthalates and microparticle formation; a causal relationship should not be inferred. Second, findings of the present study pertained to adolescents and young adults and thus may not be generalized to other populations. Further studies are needed to examine the association and clinical implication between phthalate exposure and adverse cardiovascular outcome among the elderly and other susceptible groups. Third, although we adjusted for age, gender, BMI, and health behaviors (i.e., smoking and alcohol consumption), our results could still be confounded by pre-existing medical conditions, since a complete medical history on rheumatologic and hematologic disorders and malignancies were not examined in this study. However, this omission is unlikely to affect our majoring findings since more than $95 \%$ of the participants reported that they had no medical conditions or were not currently undergoing medical treatment at the time of the study. Fourth, other 
endocrine disrupting chemicals such as polychlorinated biphenyls or bisphenol A were not accounted for in this present study and their existence may influence the outcome of the present study. Finally, the present study included MEHP, MEHHP, MEOHP, but mono-(2-ethyl-5-carboxypentyl) phthalate and mono[2-(carboxymethyl)hexyl] phthalate were not included. Thus, the level of $\Sigma$ DEHP in the present study might be underestimated.

\section{Conclusions}

We found the dose-response relationship exists between urinary concentrations of $\Sigma$ DEHP and MnBP to both EMPs and PMPs, indicating that exposure to phthalates of both low and high-molecular weight might contribute to endothelial cell apoptosis, and such damage might induce inflammatory responses; thus, subjecting those exposed to higher risk of adverse cardiovascular outcome. Future in vivo and in vitro experiment studies are warranted to elucidate the relationship between phthalate exposure and EMPs and PMPs.

Supplementary Materials: The following are available online at https:/ / doi.org/10.6084/m9.figshare. 13724860.v1. Table S1: Characteristics of the sample subjects including geometric means and 95\% confidence intervals of the $\Sigma \mathrm{DEHP}$ and $\mathrm{MnBP}{ }^{\text {a }}$, Table S2: Characteristics of the sample subjects including geometric means (GM) and 95\% confidence intervals (CI) of EMPs and PMPs, Table S3: Geometric mean (GM) values and 95\% confidence intervals (CI) for endothelial microparticle and platelet microparticle according to urinary $\Sigma$ DEHP and MnBP among participants without diabetes ${ }^{\text {a }}$.

Author Contributions: Conceptualization, methodology, data curation, investigation and resources, supervision, T.-C.S.; methodology, formal analysis, visualization, writing-original draft, writingreviewing and editing, P.-C.C.; visualization, writing — original draft, writing—reviewing and editing, C.W. All authors have read and agreed to the published version of the manuscript.

Funding: This study was supported by grants from the National Health Research Institute of Taiwan (NHRI-X95-9531PI and NHRI-X106-10629PI), the Ministry of Science and Technology of Taiwan (NSC 101-2314-B-002-184-NY3), and the Environmental Medicine Collaboration Center (EMC2), National Taiwan University Hospital, Taiwan (NTUH 103-A123).

Institutional Review Board Statement: The study was conducted according to the guidelines of the Declaration of Helsinki and approved by the Institutional Review Board of National Taiwan University Hospital (protocol code: 9561705054 and date of approval: 30 May 2006).

Informed Consent Statement: Informed consent was obtained from all subjects involved in the study.

Data Availability Statement: The data presented in this study are available on request from the corresponding author. The data are not publicly available due to privacy agreement signed by all participants.

Acknowledgments: We thank the many people who have contributed to the data we examined, including all the anonymous participants in the study.

Conflicts of Interest: The authors declare no conflict of interest.

\section{References}

1. Oehlmann, J.; Oetken, M.; Schulte-Oehlmann, U. A critical evaluation of the environmental risk assessment for plasticizers in the freshwater environment in Europe, with special emphasis on bisphenol A and endocrine disruption. Environ. Res. 2008, 108, 140-149. [CrossRef] [PubMed]

2. Lee, J.; Lee, J.-H.; Kim, C.-K.; Thomsen, M. Childhood exposure to DEHP, DBP and BBP under existing chemical manage-ment systems: A comparative study of sources of childhood exposure in Korea and in Denmark. Environ. Int. 2014, 63, 77-91. [CrossRef]

3. European Chemicals Agency. Data on Manufacture, Import, Export, Uses and Releases of Dibutylphthalate (DBP) as Well as Information on Potential Alternatives to Its Use. 2009. Available online: https:/ / echa.europa.eu/documents/10162/6ce77be0-6 c61-4e95-9241-0c262817555a (accessed on 30 December 2020).

4. European Commission. Office for Official Publications of the European Community. European Union Risk Assessment Report Dibutyl Phthalate. Available online: https:/ / echa.europa.eu/documents/10162/04f79b21-0b6d-4e67-91b9-0a70d4ea7500 (accessed on 5 December 2020).

5. Chen, X.; Xu, S.; Tan, T.; Lee, S.T.; Cheng, S.H.; Lee, F.W.-F.; Xu, S.J.L.; Ho, K.-C. Toxicity and Estrogenic Endocrine Disrupting Activity of Phthalates and Their Mixtures. Int. J. Environ. Res. Public Health 2014, 11, 3156-3168. [CrossRef] 
6. Kay, V.R.; Chambers, C.; Foster, W.G. Reproductive and developmental effects of phthalate diesters in females. Crit. Rev. Toxicol. 2013, 43, 200-219. [CrossRef]

7. David, R.M.; Moore, M.R.; Finney, D.C.; Guest, D. Chronic toxicity of di(2-ethylhexyl)phthalate in rats. Toxicol. Sci. 2000, 55, 433-443. [CrossRef]

8. Priya, V.M.; Mayilvanan, C.; Akilavalli, N.; Rajesh, P.; Balasubramanian, K. Lactational exposure of phthalate impairs insu-lin signaling in the cardiac muscle of $\mathrm{f} 1 \mathrm{female}$ albino rats. Cardiovasc. Toxicol. 2014, 14, 10-20. [CrossRef]

9. Martinez-Arguelles, D.; McIntosh, M.; Rohlicek, C.; Culty, M.; Zirkin, B.; Papadopoulos, V. Maternal in utero exposure to the endocrine disruptor di-(2-ethylhexyl) phthalate affects the blood pressure of adult male offspring. Toxicol. Appl. Pharmacol. 2013, 266, 95-100. [CrossRef]

10. Mariana, M.; Feiteiro, J.; Verde, I.; Cairrao, E. The effects of phthalates in the cardiovascular and reproductive systems: A review. Environ. Int. 2016, 94, 758-776. [CrossRef]

11. Muscogiuri, G.; Colao, A. Phtalates: New cardiovascular health disruptors? Arch. Toxicol. 2016, 91, 1513-1517. [CrossRef] [PubMed]

12. Hlisníková, H.; Petrovičová, I.; Kolena, B.; Šidlovská, M.; Sirotkin, A. Effects and Mechanisms of Phthalates' Action on Reproductive Processes and Reproductive Health: A Literature Review. Int. J. Environ. Res. Public Health 2020, 17, 6811. [CrossRef] [PubMed]

13. Amara, I.; Timoumi, R.; Annabi, E.; Neffati, F.; Najjar, M.F.; Bouaziz, C.; Abid-Essefi, S. Di (2-ethylhexyl) phthalate induces cardiac disorders in BALB/c mice. Environ. Sci. Pollut. Res. 2019, 26, 7540-7549. [CrossRef] [PubMed]

14. Ferguson, K.K.; Loch-Caruso, R.; Meeker, J.D. Exploration of Oxidative Stress and Inflammatory Markers in Relation to Urinary Phthalate Metabolites: NHANES 1999-2006. Environ. Sci. Technol. 2011, 46, 477-485. [CrossRef]

15. Horstman, L.L.; Jy, W.; Jimenez, J.J.; Ahn, Y.S. Endothelial microparticles as markers of endothelial dysfunction. Front. Biosci. 2004, 9, 118-135. [CrossRef] [PubMed]

16. Dignat-George, F.; Boulanger, C.M. The Many Faces of Endothelial Microparticles. Arterioscler. Thromb. Vasc. Biol. 2011, 31, 27-33. [CrossRef] [PubMed]

17. Chirinos, J.A.; Heresi, G.A.; Velasquez, H.; Jy, W.; Jimenez, J.J.; Ahn, E.; Horstman, L.L.; Soriano, A.O.; Zambrano, J.P.; Ahn, Y.S. Elevation of Endothelial Microparticles, Platelets, and Leukocyte Activation in Patients With Venous Thromboembolism. J. Am. Coll. Cardiol. 2005, 45, 1467-1471. [CrossRef] [PubMed]

18. Heiss, C.; Rodriguez-Mateos, A.; Kelm, M. Central Role of eNOS in the Maintenance of Endothelial Homeostasis. Antioxid. Redox Signal. 2015, 22, 1230-1242. [CrossRef]

19. Lin, C.Y.; Hsieh, C.J.; Lo, S.C.; Chen, P.C.; Torng, P.L.; Hu, A.; Sung, F.C.; Su, T.C. Positive association between concentra-tion of phthalate metabolites in urine and microparticles in adolescents and young adults. Environ. Int. 2016, 92, 157-164. [CrossRef]

20. Melki, I.; Tessandier, N.; Zufferey, A.; Boilard, E. Platelet microvesicles in health and disease. Platelets 2017, 28, 214-221. [CrossRef]

21. Bulut, D.; Maier, K.; Bulut-Streich, N.; Börgel, J.; Hanefeld, C.; Mügge, A. Circulating Endothelial Microparticles Correlate Inversely With Endothelial Function in Patients With Ischemic Left Ventricular Dysfunction. J. Card. Fail. 2008, 14, 336-340. [CrossRef] [PubMed]

22. Kataria, A.; Levine, D.; Wertenteil, S.; Vento, S.; Xue, J.; Rajendiran, K.; Kannan, K.; Thurman, J.M.; Morrison, D.; Brody, R.; et al. Exposure to bisphenols and phthalates and association with oxidant stress, insulin resistance, and endothelial dysfunction in children. Pediatr. Res. 2017, 81, 857-864. [CrossRef]

23. Tsai, C.W.; Kuo, C.C.; Wu, C.F.; Chien, K.L.; Wu, V.C.; Chen, M.F.; Sung, F.C.; Su, T.C. Associations of renal vascular re-sistance with albuminuria in adolescents and young adults. Nephrol. Dial. Transplant. 2011, 26, 3943-3949. [CrossRef]

24. Su, T.C.; Liao, C.C.; Chien, K.L.; Hsu, S.H.; Sung, F.C. An overweight or obese status in childhood predicts subclinical atherosclerosis and prehypertension/hypertension in young adults. J. Atheroscler. Thromb. 2014, 21, 1170-1182. [CrossRef] [PubMed]

25. US Department of Health and Human Services, National Institutes of Health. The Fourth Report on the Diagnosis, Evaluation, and Treatment of High Blood Pressure in Children and Adolescents; US Department of Health and Human Services: Washington, DC, USA, 2005.

26. World Health Organization; Office of Occupational Health. Biological Monitoring of Chemical Exposure in the Workplace: Guidelines; World Health Organization: Geneva, Switzerland, 1996.

27. Su, T.-C.; Hwang, J.-S.; Torng, P.-L.; Wu, C.; Lin, C.-Y.; Sung, F.-C. Phthalate exposure increases subclinical atherosclerosis in young population. Environ. Pollut. 2019, 250, 586-593. [CrossRef] [PubMed]

28. US Department of Health and Human Services, Centers for Disease Control and Prevention. Fourth National Report on Human Exposure to Environmental Chemicals; US Department of Health and Human Services: Washington, DC, USA, 2009.

29. Chirinos, J.A.; Zambrano, J.P.; Virani, S.S.; Jimenez, J.J.; Jy, W.; Ahn, E.; Horstman, L.L.; Castellanos, A.; Myerburg, R.J.; Ahn, Y.S. Correlation Between Apoptotic Endothelial Microparticles and Serum Interleukin-6 and C-Reactive Protein in Healthy Men. Am. J. Cardiol. 2005, 95, 1258-1260. [CrossRef]

30. Zhao, Y.; Shi, H.; Xie, C.-Q.; Chen, J.; Laue, H.; Zhang, Y. Prenatal phthalate exposure, infant growth, and global DNA methylation of human placenta. Environ. Mol. Mutagenesis 2014, 56, 286-292. [CrossRef]

31. Kim, Y.A.; Kho, Y.; Chun, K.-C.; Koh, J.W.; Park, J.W.; Bunderson-Schelvan, M.; Cho, Y.H. Increased Urinary Phthalate Levels in Women with Uterine Leiomyoma: A Case-Control Study. Int. J. Environ. Res. Public Health 2016, 13, 1247. [CrossRef] 
32. Watkins, D.J.; Eliot, M.; Sathyanarayana, S.; Calafat, A.M.; Yolton, K.; Lanphear, B.P.; Braun, J.M. Variability and Predictors of Urinary Concentrations of Phthalate Metabolites during Early Childhood. Environ. Sci. Technol. 2014, 48, 8881-8890. [CrossRef]

33. Hartopo, A.B.; Puspitawati, I.; Gharini, P.P.; Setianto, B.Y. Platelet microparticle number is associated with the extent of myocardial damage in acute myocardial infarction. Arch. Med. Sci. 2016, 12, 529-537. [CrossRef] [PubMed]

34. Yel, S.; Dursun, İ.; Çetin, F.; Baştuğ, F.; Tülpar, S.; Düşünsel, R.; Gündüz, Z.; Poyrazoğlu, H.; Y1lmaz, K. Increased circulating endothelial microparticles in children with fmf. Biomarkers 2018, 23, 558-562. [CrossRef] [PubMed]

35. Pastore, I.; Bolla, A.M.; Montefusco, L.; Lunati, M.E.; Rossi, A.; Assi, E.; Zuccotti, G.V.; Fiorina, P. The Impact of Diabetes Mellitus on Cardiovascular Risk Onset in Children and Adolescents. Int. J. Mol. Sci. 2020, 21, 4928. [CrossRef] [PubMed]

36. Oda, N.; Kajikawa, M.; Maruhashi, T.; Kishimoto, S.; Yusoff, F.M.; Goto, C.; Nakashima, A.; Tomiyama, H.; Takase, B.; Yamashina, A.; et al. Endothelial function is preserved in light to moderate alcohol drinkers but is impaired in heavy drinkers in women: Flow-mediated Dilation Japan (FMD-J) study. PLoS ONE 2020, 15, e0243216. [CrossRef]

37. Sangha, G.S.; Goergen, C.J.; Ranadive, S.M.; Prior, S.J.; Clyne, A.M. Preclinical Techniques to Investigate Exercise Training in Vascular Pathophysiology. Am. J. Physiol. Circ. Physiol. 2021. [CrossRef] [PubMed]

38. Cooper, D.C.; Milic, M.S.; Mills, P.J.; Bardwell, W.A.; Ziegler, M.G.; Dimsdale, J.E. Endothelial function: The impact of objec-tive and subjective socioeconomic status on flow-mediated dilation. Ann. Behav. Med. 2010, 39, 222-231. [CrossRef] [PubMed]

39. Burnouf, T.; Goubran, H.A.; Chou, M.-L.; Devos, D.; Radosevic, M. Platelet microparticles: Detection and assessment of their paradoxical functional roles in disease and regenerative medicine. Blood Rev. 2014, 28, 155-166. [CrossRef]

40. Deng, F.; Wang, S.; Zhang, L. Endothelial microparticles act as novel diagnostic and therapeutic biomarkers of circulatory hypoxia-related diseases: A literature review. J. Cell. Mol. Med. 2017, 21, 1698-1710. [CrossRef]

41. Cardama, A.L.; De Quirós, A.R.B.; Bustos, J.; Lomo, M.L.; Losada, P.P.; Sendón, R. Estimation of Dietary Exposure to Contaminants Transferred from the Packaging in Fatty Dry Foods Based on Cereals. Foods 2020, 9, 1038. [CrossRef]

42. European Commission; Office for Official Publications of the European Community. European Union Risk Assessment Report BIS(2-ETHYLHEXYL) PHTHALATE (DEHP). 2008. Available online: https:/ / echa.europa.eu/documents/10162/e614617d-58e7 -42d9-b7fb-d7bab8f26feb (accessed on 5 December 2020).

43. Fierens, T.; Standaert, A.; Cornelis, C.; Sioen, I.; De Henauw, S.; Willems, H.; Bellemans, M.; De Maeyer, M.; Van Holderbeke, M. A semi-probabilistic modelling approach for the estimation of dietary exposure to phthalates in the belgian adult popula-tion. Environ. Int. 2014, 73, 117-127. [CrossRef]

44. Huang, P.-C.; Tsai, C.-H.; Liang, W.-Y.; Li, S.-S.; Pan, W.-H.; Chiang, H.-C. Age and Gender Differences in Urinary Levels of Eleven Phthalate Metabolites in General Taiwanese Population after a DEHP Episode. PLoS ONE 2015, 10, e0133782. [CrossRef]

45. Zhao, J.F.; Hsiao, S.H.; Hsu, M.H.; Pao, K.C.; Kou, Y.R.; Shyue, S.K.; Lee, T.S. Di-(2-ethylhexyl) phthalate accelerates atherosclerosis in apolipoprotein e-deficient mice. Arch. Toxicol. 2016, 90, 181-190. [CrossRef]

46. Su, T.-C.; Hwang, J.-J.; Sun, C.-W.; Wang, S.-L. Urinary phthalate metabolites, coronary heart disease, and atherothrombotic markers. Ecotoxicol. Environ. Saf. 2019, 173, 37-44. [CrossRef] [PubMed]

47. Ferguson, K.K.; Cantonwine, D.E.; Rivera-González, L.O.; Loch-Caruso, R.; Mukherjee, B.; Del Toro, L.V.A.; Jiménez-Vélez, B.; Calafat, A.M.; Ye, X.; Alshawabkeh, A.N.; et al. Urinary Phthalate Metabolite Associations with Biomarkers of Inflammation and Oxidative Stress Across Pregnancy in Puerto Rico. Environ. Sci. Technol. 2014, 48, 7018-7025. [CrossRef] [PubMed]

48. Shiue, I. Urine phthalate concentrations are higher in people with stroke: United states national health and nutrition exami-nation surveys (nhanes), 2001-2004. Eur. J. Neurol. 2013, 20, 728-731. [CrossRef] [PubMed]

49. Osman, A.M.; van Dartel, D.A.; Zwart, E.; Blokland, M.; Pennings, J.L.; Piersma, A.H. Proteome profiling of mouse embry-onic stem cells to define markers for cell differentiation and embryotoxicity. Reprod. Toxicol. 2010, 30, 322-332. [CrossRef]

50. Dursun, I.; Düsünsel, R.; Poyrazoglu, H.M.; Gunduz, Z.; Patıroglu, T.; Ülger, H.; Gurgoze, M.K. Circulating endothelial mi-croparticles in children with henoch-schönlein purpura; preliminary results. Rheumatol. Int. 2011, 31, 1595-1600. [CrossRef]

51. Dursun, I.; Poyrazoglu, H.M.; Gunduz, Z.; Ulger, H.; Yýkýlmaz, A.; Dusunsel, R.; Patýroglu, T.; Gurgoze, M. The relation-ship between circulating endothelial microparticles and arterial stiffness and atherosclerosis in children with chronic kidney disease. Nephrol. Dial. Transplant. 2009, 24, 2511-2518. [CrossRef]

52. Gündüz, Z.; Dursun, İ.; Tülpar, S.; Baştuğ, F.; Baykan, A.; Yıkılmaz, A.; Patıroğlu, T.; Poyrazoglu, H.M.; Akın, L.; Yel, S. In-creased endothelial microparticles in obese and overweight children. J. Pediatric Endocrinol. Metab. 2012, 25, 1111-1117. [CrossRef]

53. Yang, G.; Zhou, X.; Wang, J.; Zhang, W.; Zheng, H.; Lu, W.; Yuan, J. MEHP-induced oxidative DNA damage and apoptosis in HepG2 cells correlates with p53-mediated mitochondria-dependent signaling pathway. Food Chem. Toxicol. 2012, 50, $2424-2431$. [CrossRef] [PubMed]

54. Trasande, L.; Sathyanarayana, S.; Trachtman, H. Dietary phthalates and low-grade albuminuria in us children and adoles-cents. Clin. J. Am. Soc. Nephrol. 2014, 9, 100-109. [CrossRef] [PubMed]

55. Yang, J.; Hauser, R.; Goldman, R.H. Taiwan food scandal: The illegal use of phthalates as a clouding agent and their contri-bution to maternal exposure. Food Chem. Toxicol. 2013, 58, 362-368. [CrossRef]

56. Bammert, T.D.; Hijmans, J.G.; Kavlich, P.J.; Lincenberg, G.M.; Reiakvam, W.R.; Fay, R.T.; Greiner, J.J.; Stauffer, B.L.; DeSou-za, C.A. Influence of sex on the number of circulating endothelial microparticles and microrna expression in middle-aged adults. Exp. Physiol. 2017, 102, 894-900. [CrossRef]

57. Enjeti, A.K.; Ariyarajah, A.; D'Crus, A.; Seldon, M.; Lincz, L.F. Circulating microvesicle number, function and small rna con-tent vary with age, gender, smoking status, lipid and hormone profiles. Thromb. Res. 2017, 156, 65-72. [CrossRef] [PubMed] 
58. Vafeiadi, M.; Myridakis, A.; Roumeliotaki, T.; Margetaki, K.; Chalkiadaki, G.; Dermitzaki, E.; Venihaki, M.; Sarri, K.; Vassilaki, M.; Leventakou, V.; et al. Association of Early Life Exposure to Phthalates With Obesity and Cardiometabolic Traits in Childhood: Sex Specific Associations. Front. Public Health 2018, 6, 327. [CrossRef] [PubMed]

59. Buser, M.C.; Murray, H.E.; Scinicariello, F. Age and sex differences in childhood and adulthood obesity association with phthalates: Analyses of NHANES 2007-2010. Int. J. Hyg. Environ. Health 2014, 217, 687-694. [CrossRef] [PubMed] 